On the basis of this study of reaction and decomposition velocities, we selected $70^{\circ}$ as the optimum temperature for equilibrium measurements. Working at this temperature we showed that our method of analysis was efficient, and that a true equilibrium was established in the solution. Selecting the chloride for a more extended study we varied the concentrations both of the reacting substances and of the other chlorides present and showed that the equilibrium is affected both by the total concentration of the salt and by the concentration of the chlorine ion; it is, however, independent of the acidity of the solution.

We calculated the concentrations of the various molecular species present in the equilibrium mixtures and applied the simple concentration law to the various possible equilibria which might exist between them. No satisfactory equilibrium constant was obtained. When, however, the equilibrium was viewed as an electrolytic dissociation of purpureo compounds into roseo compounds and chlorine ions, and their concentrations were substituted in the Storch-Bancroft modification of the concentration law, an approximate constant was obtained; a further modification of this law gave an excellent constant. We pointed out that if this view is correct we have the interesting case of a slow electrolytic dissociation. Furthermore, we know that the chlorine ion given off by the purpureo radical is replaced by a water molecule; by analogy the same thing would be expected in the dissociation of an ordinary electrolyte.

Finally, it was shown that in the dry state the roseo salts have a critical aqueous vapor pressure above which only a very slow loss of water occurs. The change does not appear to be reversible. It was further shown that the change is necessarily connected with the absorption or evolution of water.

We are carrying out measurements, similar to those described in this paper, on the ammines of chromium, iridium and rhodium and on the complex salts of cobalt and other metals with ethylenediammine.

NEW YORK CITY.

[CONtribution from the Chemical Laboratories of Clark University.]

\title{
A RE-INVESTIGATION OF THE VELOCITY OF SUGAR HYDROLYSIS.
} FIRST COMMUNICATION.

By M. A. Rosanoff, R. H. CIARK, AND R. L. Sibley.

Received October I4, IgII.

\section{Introductory.}

The mechanism of sugar hydrolysis is as yet scarcely understood. Even as to the number of molecules that take part in the hydrolysis physico-chemical literature contains but incomplete information. Most investigators have, namely, found the reaction to be monomolecular with respect to sugar. There is some evidence also that the process in- 
volves the catalytic activity of one hydrogen ion. Finally, it is believed that the reaction is monomolecular with respect to water; but on this last point there are no experimental data.

In I904 Armstrong and Caldwell ${ }^{1}$ published a study of the hydrolysis of cane sugar by very dilute acids, from which it appears that even with respect to the sugar the reaction is not strictly monomolecular throughout its course, that in the earlier stages the reaction does not obey the mass law at all, the velocity coefficient showing a regular increase. Armstrong and Caldwell's measurements were numerous and skilfully carried out.

Four years later Julius Meyer ${ }^{2}$ carried out similar measurements and likewise found the velocity coefficient changing during the eatly stage of the reaction. Meyer's coefficients, however, showed, not an increase, but a gradual decrease. Meyer believed that his results could be fully explained by assuming that the hydrolysis is complicated by a pair of side reactions taking place simultaneously with it: namely, the mutarotation of glucose and of fructose.

Meyer's measurements have been criticized by Hudson, ${ }^{3}$ who justly points out that mutarotation can only lead to an increasing velocity coefficient, although, on the other hand, increase of the coefficient might also be caused by variation of the specific rotation of fructose with its concentration. He believes that Meyer's decreasing coefficients can only be explained by experimental errors. He agrees, however, that "the hydrolysis of cane sugar is not the simple reaction that it has heretofore been supposed to be, but is accompanied by two other important reactions." 4

Hudson ${ }^{5}$ accepts Armstrong and Caldwell's results, but thinks "the matter still in doubt as to whether Armstrong and Caldwell's deviation is due to mutarotation, change of rotation of fructose, or a true exception to the law of mass action, which latter view is the one that Armstrong and Caldwell hold."

That sugar hydrolysis is either a complex process, or else forms an exception to the law of mass action, might also be concluded from a phenomenon described by Ostwald a quarter of a century ago. ${ }^{6}$ If the hydrolysis is monomolecular with respect to stgar, and the amount of water present is relatively large, the rate of the reaction should follow the monomolecular equation of mass action. According to this equation, the velocity coefficient must be independent of the initial concentration

1 Proc. Roy. Soc. London, 74, I95 (1904).

${ }^{2} Z$. physik. Chem., 62, 59 (1908); see also Ibid., 72, XI7 (IgIO).

3 This Journal, 30, II65 (I908); 32, 885 (IgIO).

4 Ibid., 32, 886 (1910).

${ }^{5}$ Ibid., 889.

o J.prakt. Chem., 31, 3I6 (I885). 
of the sugar. Ostwald, however, states that the velocity coefficient increases rapidly with the initial sugar concentration. For example, using hydrochloric acid of one and the same concentration ( 0.5 normal) as a catalyzer, he obtained:

$\begin{array}{cc}\begin{array}{c}\text { Initial concentration } \\ \text { of sugar. } \\ \text { Per cent. }\end{array} & \begin{array}{c}\text { Velocity } \\ \text { coefficient k. }\end{array} \\ 4 & 19.14 \\ \text { IO } & 20.63 \\ 20 & 22.87 \\ 40 & 29.16\end{array}$

In connection with these figures Ostwald observes: "The velocity constants change with the quantity of sugar almost in the ratio of three to two. It is, therefore, doubtless that the process of inversion is subject to the influence of side reactions, which manifest themselves the more clearly, the more concentrated the solutions."

Figures similar to Ostwald's have been published by Spohr. ${ }^{1}$ A theory of the variation has been introduced by Arrhenius. ${ }^{2}$

\section{Does the Velocity of Sugar Inversion Depend upon the Initial Concen- tration of the Sugar?}

The first part or our re-investigation of the subject deals with the role played by the sugar and is reported in the present communication. ${ }^{3}$

The comparative measurements of Ostwald, Spohr, and others were carried out on solutions prepared in a manner equivalent to adding equal amounts of acid to equal volumes of a standard sugar solution and diluting with water, respectively, to twice, four times, etc., the original volume. The solutions of unequal sugar concentrations were, therefore, equally concentrated with respect to acid. But they contained unequal quantities of water per unit volume.

The effect of unequal quantities of water upon the catalytic power of an acid is as yet unknown. And so it seemed desirable to carry out new measurements, keeping the concentrations of both acid and water constant. Such is very nearly the case during the hydrolysis of any one given solution, and then the velocity coefficient remains constant. This constancy has been explained by assuming that the invert sugar, which gradually replaces the cane sugar, has a specific catalytic influence, similar to that of cane sugar itself, upon the rate of hydrolysis.

In order to ascertain more definitly whether the cause lies in such a specific influence of invert sugar, or in the constancy of the concentration of both acid and water, we prepared three pairs of solutions, acid

$1 J$. prakt. Chem., 33, 266 (1886). (1897).

2Z. physik. Chem., 28, 319 (1899). See also Ernst Cohen, Ibid., 23, 442

${ }^{3}$ Further parts, dealing with the role played by water, acid, and neutral salts, will follow in communications from these laboratories as soon as practicable. 
and water having exactly the same concentration in each pair, but the sugar in one solution of each pair being replaced, in part, by glucose, mannitol, or acetone. In order to make the volumes of two solutions of a pair exactly alike, preliminary experiments were carried out, to show how much glucose, or mannitol, or acetone, as the case might be, must be added in place of part of the cane sugar to make the volume equal to that of the comparison solution containing none of the foreign substance. These data enabled us to weigh out precisely the quantities of the ingredients needed for every final experiment, warm them separately to the required temperature, and mix them rapidly at the beginning of the experiment. The rotations during hydrolysis were measured, for the most part, with an excellent half-shade quartz wedge compensation saccharimeter kindly placed at our disposal by Dr. William D. Horne, of the National Refining Company, Yonkers, N. Y. We wish to express here again our gratitude to Dr. Horne for his courtesy and generosity.

The temperature of the reacting mixtures was kept constant at $30^{\circ} \pm$ $0.02^{\circ}$. To avoid disturbances, the rotations were observed at the same temperature, $30^{\circ}$, the instrument used being inclosed in a wooden box within which this temperature was maintained sufficiently constant. Under these circumstances, our results can have no claim to high precision, but they are precise enough for the purposes of the problem. Kahlbaum's best formic acid, which we found to be 99.2 per cent. strong, was used in all except our two acetone experiments (an approximately 85 per cent. commercial acid was used in the acetone series). No further purification was required, for obvious reasons.

The results which we were aiming to obtain would plainly be the more decisive the greater the difference between the initial sugar concentrations of each pair of solutions. In our experiments these differences were limited by the solubilities involved.

In the tables below, $t$ denotes the time in hours, $\alpha$ is the rotation ob-

TABle I.-The Solution Contaned 50.500 Grams Cane Sugar, I95.73 Grams WATER, AND 28.750 Grams Formic ACID ( 99.2 PER CENT.) IN $250 \mathrm{cC}$.

\begin{tabular}{|c|c|c|c|c|c|}
\hline t. & {$\left[7^{\alpha .} .00^{\circ}\right]$} & $\begin{array}{l}k \\
\ldots\end{array}$ & $\begin{array}{r}t . \\
37\end{array}$ & $\begin{array}{r}\alpha . \\
6.45\end{array}$ & $\begin{array}{c}k \\
0.0150\end{array}$ \\
\hline 2 & 71.00 & 0.0159 & 42 & $2 \cdot 30$ & I 49 \\
\hline 3 & 68. I0 & I52 & $4^{8}$ & -1.95 & I 49 \\
\hline 4 & $65 \cdot 10$ & I5I & 52 & -4.05 & 147 \\
\hline 5 & 62.30 & 150 & $6 I$ & -9.00 & 149 \\
\hline 7 & 56.70 & I 50 & 72 & -12.90 & I 50 \\
\hline $9 \cdot 5$ & 50.55 & 148 & 86 & -15.80 & 147 \\
\hline 12 & 44.60 & I 49 & 95 & -17.25 & I 50 \\
\hline I 5 & 38.25 & I 48. & II 2 & -19.30 & I 54 \\
\hline 8 & 32.40 & 148 & $\infty$ & -21.15 & . \\
\hline $2 I$ & $27 \cdot 35$ & 148 & & & {[} \\
\hline 24 & 22.45 & I 49 & & Average, & $0.015^{\circ}$ \\
\hline 28 & 17.10 & 148 & & & \\
\hline
\end{tabular}


served, and $k$ is the velocity constant of the monomolecular mass law equation, calculated by the formula

$$
k=\frac{\mathrm{I}}{t} \log _{10} \frac{\alpha_{0}-\alpha_{\infty}}{\alpha-\alpha_{\infty}},
$$

where $\alpha_{0}$ and $\alpha_{\infty}$ denote, as usual, the initial and final rotations respectively. The initial rotations $(t=0)$, enclosed in brackets, were calculated as explained in Section 3 .

Table II.-The Solution Contained I 4.250 Grams Cane Sugar, 35.000 Grams Glucose, 195.73 Grams Water, ANd 28.750 Grams Formic Acid in $250 \mathrm{cc}$.

\begin{tabular}{|c|c|c|c|c|c|}
\hline$t$ & $\alpha$. & $k$. & $t$ & $\alpha$. & $k$. \\
\hline o & {$\left[66.40^{\circ}\right]$} & .. & 24 & 50.75 & $0.015^{2}$ \\
\hline 2 & 64.60 & O.OI5I & 27 & 49.65 & I 5 I \\
\hline 3 & 63.70 & $I_{52}$ & $3 I$ & $4^{8} \cdot 35$ & I 50 \\
\hline 4 & 62.90 & I 50 & 37 & 46.70 & I 48 \\
\hline 5 & 62.10 & I 49 & 43 & 45.20 & I 49 \\
\hline 6.5 & 60.90 & I 50 & $5 \mathrm{I}$ & 43.65 & I 49 \\
\hline 8 & 59.80 & 150 & 55 & 43.05 & I 50 \\
\hline IO & $5^{8} \cdot 5^{\circ}$ & 147 & 64 & $4 I \cdot 70$ & I 55 \\
\hline I 2 & 57 . IO & I 50 & 75 & 40.70 & I 50 \\
\hline I 8 & $53 \cdot 55$ & I 52 & 89 & 40.05 & I 55 \\
\hline $2 \mathrm{I}$ & 52.15 & I 5 I & $\infty$ & 38.90 & $\cdots$ \\
\hline
\end{tabular}

The velocity coefficients in the two comparison series given by Tables I and II are obviously identical. The initial sugar concentrations are in the ratio of 3.54 to $I$.

TABle III.-The Solution Contained 37.613 Grams Cane Sugar, 203.44 Grams WATER, AND $28.75^{\circ}$ GRAMS Formic ACID iN $250 \mathrm{cC}$.

$\left[57.90^{\circ}\right]$

55 . 10

$53 \cdot 15$

50.80

$+8.50$

46.50

$44 \cdot 40$

$40 \cdot 50$

38.70

$35 \cdot 20$

31.80

28.90

23.80

20.70

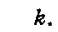

$k$.
$\cdots$
0.0169
146
147
149
147
147
147
146
$I 46$
$I 47$
$I 46$
$I 45$
146

$t$.
24
27
31
35
40
46
52
60
66
74
85
95
112
$\infty$

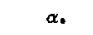

I6.95

13.50

IO. 10

6.75

3.40

$-0.40$

$-2.95$

- 5.90

$-7.45$

$-9.40$

-II.25

-I2.60

-I 3.80

-I 5.45 b.

0.0148

I 49

146

I 48

I 47

I 49

148

I 47

I 46

I 46

I 46

I 49

I 47

$$
\text { Average, } 0.0147
$$


Table IV.-The Solution Contained I4.250 Grams Cane Sugar, 22.000 Grams Mannitol, 203.44 Grams Water, AND 28.750 Grams Formic Acid in $250 \mathrm{cC}$.

\begin{tabular}{|c|c|c|c|c|c|}
\hline t. & $\alpha$ & $k$ & $t$ & $\alpha$. & $k$. \\
\hline o & {$\left[22.10^{\circ}\right]$} & . & 30 & $4 \cdot 50$ & 0.0147 \\
\hline I & $2 \mathrm{I} . \mathrm{IO}$ & 0.0160 & 34 & 3.25 & 147 \\
\hline 2 & 20.30 & I 46 & 39 & I. 90 & I 46 \\
\hline $3 \cdot 5$ & 19.00 & $\mathrm{I} 48$ & 45 & 0.35 & I 49 \\
\hline 5 & 17.85 & I 45 & $5 \mathrm{I}$ & $\multimap 0.55$ & I49 \\
\hline 8 & I 5.60 & I 46 & 59 & -1.80 & 146 \\
\hline IO & 14.15 & $\mathrm{I} 48$ & 65 & -2.50 & 148 \\
\hline I 2 & I 2.90 & 147 & 73 & -3.20 & 148 \\
\hline I 5 & II. IO & 147 & 84 & -3.90 & I 48 \\
\hline 17 & 10.05 & I 46 & 94 & $-4 \cdot 30$ & I 47 \\
\hline 20 & 8.65 & 145 & I I I & -4.85 & I45 \\
\hline 23 & 7.25 & $\mathrm{I} 46$ & I33 & -5.10 & I 47 \\
\hline 26 & 6.00 & 146 & $\infty$ & $-5 \cdot 50$ & .. \\
\hline
\end{tabular}

The velocity coefficients in the two comparison series given by Tables III and IV are again equal. The initial sugar concentrations are in the ratio of 2.64 to $\mathrm{I}$.

A third pair of solutions, with acetone used to equalize the volumes, and again with the acid and water concentrations equal, gave a similar result: the two velocity coefficients were practically identical. In this case it seemed desirable to have some acetone in both solutions, to avoid too abrupt a difference in the nature of the reacting medium. An aqueous commercial acid was employed. Unfortunately, the determination of its exact strength was prevented by accident, and therefore the measurements will not be reported in detail.

The results given in Tables I to IV (together with the results of the acetone series just mentioned) show that the constancy of the velocity coefficient of sugar hydrolysis is not due to any specific effect of the invert sugar which gradually replaces the cane sugar in an ordinary single experiment. Glucose, mannitol, and acetone, and presumably any other inert substance, may be introduced in place of more or less of the cane sugar, and the velocity coefficient will be the same, as long as the concentrations of both water and acid remain unchanged. The velocity coefficient is independent of the initial concentration of the sugar itself.

\section{Do Armstrong and Caldwell's Results Indicate Either Side Reactions or Deviation from the Law of Mass Action?}

As before stated, Armstrong and Caldwell found a regular increase of the velocity coefficient in the early stages of sugar hydrolysis. The following circumstance, however, led us to suspect that their varying values of $k$ might be only apparent; due, not to complicating side-reactions, 
or deviations from the mass law, but to slight errors in the assumed values of $\alpha_{0}$. If, namely,

$$
k=\frac{I}{t} \ln \frac{\alpha_{0}-\alpha_{\infty}}{\alpha-\alpha_{\infty}},
$$

then, for a given set of values of $t, \alpha$, and $\alpha_{\infty}$ (since slight changes of $\alpha_{0}$ leave the difference $\alpha_{0}-\alpha_{\infty}$ practically constant),

$$
\frac{d k}{d \alpha_{0}}=\frac{\mathrm{I}}{t\left(\alpha_{0}-\alpha_{\infty}\right)}=\frac{\mathrm{I}}{t} \times \text { constant. }
$$

In words: the effect of an error in the initial reading $\alpha_{0}$ upon the value of the velocity constant $k$ is inversely proportional to the time elapsed since the beginning of the reaction. This means that even a slight error in the value of $\alpha_{0}$ assumed in computing $k$ is liable to lead to grossly erroneous values of $k$ for the earliest stages of the reaction (especially in dilute solutions, where $\alpha_{0}-\alpha_{\infty}$ is small). The error rapidly decreases and becomes inappreciable for the more advanced stages of the reaction.

A far more reliable value of $\alpha_{0}$ than can be obtained by direct observation may be calculated as follows: The ordinary monomolecular equation

is written in the form

$$
k=\frac{\mathrm{I}}{t} \log _{10} \frac{\alpha_{0}-\alpha_{\infty}}{\alpha-\alpha_{\infty}}
$$

$$
\log _{10}\left(\alpha-\alpha_{\infty}\right)=\mathrm{A}+\mathrm{B} t
$$

the best values of $A$ and $B$ are obtained by applying the method of least squares to all the observations of a given series, and $\alpha_{0}$ is readily found from $\mathrm{A}=\log _{10}\left(\alpha_{0}-\alpha_{\infty}\right)$. The value of $\alpha_{0}$ is then as reliable as that of $\alpha_{\infty}$, which can be observed at leisure with all possible care.

Another way, based on the same principle, consists in plotting, on as large a scale as possible, the available values of $\log _{10}\left(\alpha-\alpha_{\infty}\right)$, against the corresponding values of $t$, and extrapolating to $t=0$ to find $\log _{10}\left(\alpha_{0}-\alpha_{\infty}\right)$, and hence $\alpha_{0}$. Armstrong and Caldwell's results, when plotted in this manner on a large scale, yielded perfectly straight lines for all series, without the slightest indication of curvature anywhere (see Table IX), demonstrating sugar hydrolysis to be a simple reaction, monomolecular with respect to sugar, and free from disturbing (i. e., relatively slow) mutarotation reactions or other side-reactions throughout its course (see Section 4 below).

The figures given in the following tables were obtained from values of $\alpha_{0}$ (enclosed in brackets) yielded by the method of least squares. That Armstrong and Caldwell's observed values of $\alpha_{0}$ are erroneous, and that our calculated values are much more reliable, is clearly indicated by the data reproduced in Tables V and VI. The solutions corresponding to these tables had identically the same final rotation, $-5.37^{\circ}$, and hence must have been identical in composition. Yet the observed initial ro- 
tations were respectively $22.22^{\circ}$ and $22.12^{\circ}$. On the other hand, our calculated values, $22.28^{\circ}$ and $22.26^{\circ}$, are practically equal. ${ }^{1}$

Table V.-Armstrong and Caldwell's Results (loc. cit., p. i97) Recalculated.

\begin{tabular}{|c|c|c|c|c|c|c|c|}
\hline $\begin{array}{l}t \\
\mathrm{o}\end{array}$ & {$\left[\begin{array}{c}\alpha . \\
{\left[22.28^{\circ}\right]}\end{array}\right.$} & $\begin{array}{c}k(\mathrm{~A}, \& \mathrm{C}){ }^{2} \\
\ldots\end{array}$ & $\begin{array}{c}k(\text { recalc. }) \\
\ldots\end{array}$ & $\begin{array}{c}t . \\
240\end{array}$ & $\begin{array}{l}\alpha . \\
16.17\end{array}$ & $\begin{array}{l}k(\text { A. \& C. }) .{ }^{2} \\
0.000448\end{array}$ & $\begin{array}{c}k \text { (recalc.). } \\
0.000456\end{array}$ \\
\hline 15 & 21.83 & 0.000412 & $\left(0.00047^{2}\right)^{3}$ & 255 & $15 \cdot 7^{8}$ & 453 & $45^{8}$ \\
\hline 30 & $21 \cdot 40$ & 437 & $(467)$ & 270 & I 5.43 & 454 & 462 \\
\hline 45 & 21.00 & 437 & $45^{6}$ & 285 & 15.05 & 459 & $45^{6}$ \\
\hline 60 & 20.63 & 430 & 445 & 345 & $\mathrm{I} 3.87$ & 455 & 456 \\
\hline 75 & 20.18 & 445 & 457 & 360 & 13.57 & 454 & $45^{8}$ \\
\hline 90 & 19.77 & 449 & 459 & 375 & I 3.25 & 455 & $45^{8}$ \\
\hline 105 & 19.45 & 438 & 446 & 390 & 12.95 & 456 & 459 \\
\hline I 20 & 19.00 & 449 & 457 & $4 \circ 5$ & 12.65 & 457 & 456 \\
\hline I 35 & 18.63 & 448 & 455 & 420 & I 2.42 & 454 & 457 \\
\hline 150 & 18.27 & 447 & 453 & 435 & 12.13 & 454 & 457 \\
\hline I 65 & $17 \cdot 92$ & 446 & $45^{2}$ & $45^{\circ}$ & I I . 85 & 453 & 457 \\
\hline I 80 & $I 7 \cdot 5^{2}$ & $45 \mathrm{I}$ & $45^{6}$ & 465 & 11.58 & 455 & 457 \\
\hline 195 & I 7.18 & 449 & 454 & 480 & I I . 32 & 455 & 456 \\
\hline 210 & I 6.83 & 450 & 455 & 495 & 11.07 & 454 & 457 \\
\hline \multirow[t]{3}{*}{225} & 16.47 & $45 I$ & $45^{2}$ & 510 & 10.80 & 455 & 455 \\
\hline & & & & $\infty$ & $-5 \cdot 37$ & .. & $\ldots$ \\
\hline & & & & & & Average, & $0.00045^{6}$ \\
\hline
\end{tabular}

TABle VI.-ARMstrong and CALdweli's Results (Loc. cit., p. 197) Recalculated.

\begin{tabular}{|c|c|c|c|c|c|c|c|}
\hline t. & $\begin{array}{c}\alpha . \\
{\left[22.26^{\circ}\right]}\end{array}$ & $\begin{array}{c}k(\text { A. } \& \text { C. })^{4} \\
\ldots\end{array}$ & $\begin{array}{c}k \text { (recalc. }) \\
\ldots\end{array}$ & $\begin{array}{l}t . \\
270\end{array}$ & $\begin{array}{c}\alpha . \\
15.60\end{array}$ & $\begin{array}{r}k\left(\text { A. \& C. } .^{2}\right. \\
0.000435\end{array}$ & $\begin{array}{l}k \text { (recale.) } \\
0.000445\end{array}$ \\
\hline 15 & 21.73 & 0.000414 & $(0.000564)$ & 285 & I 5.27 & 437 & 446 \\
\hline 30 & $21 \cdot 35$ & $4 \mathrm{II}$ & $(486)$ & 300 & $\mathrm{r} 4.93$ & 439 & 446 \\
\hline 45 & 20.97 & 412 & $(462)$ & 315 & 14.63 & $43^{8}$ & 447 \\
\hline 60 & $20.5^{8}$ & 417 & 453 & 330 & $14 \cdot 30$ & $44 \mathrm{I}$ & 444 \\
\hline 75 & 20.22 & 415 & 455 & 345 & 13.95 & 444 & 449 \\
\hline 90 & 19.82 & 422 & 447 & 360 & I3.68 & 442 & 448 \\
\hline 105 & 19.45 & 423 & 444 & 375 & I $3 \cdot 35$ & 443 & 448 \\
\hline 120 & 19.03 & 431 & $45^{\circ}$ & 390 & I3. IO & 445 & 449 \\
\hline 135 & 18.72 & 425 & $44 \mathrm{I}$ & 405 & I 2.83 & 442 & 447 \\
\hline I 50 & 1 8.37 & 425 & 440 & 420 & 12.53 & 444 & 449 \\
\hline I 65 & I 8.00 & 427 & $44 \mathrm{I}$ & 435 & 12.23 & 445 & 450 \\
\hline 180 & 17.60 & 433 & 446 & $45^{\circ}$ & I I .97 & 445 & $45^{\circ}$ \\
\hline 195 & 17.23 & 436 & 448 & 465 & II. 73 & 443 & 448 \\
\hline 210 & 16.90 & 435 & 446 & 480 & I I . 48 & 443 & 448 \\
\hline 225 & 16.60 & 433 & 443 & 495 & I I. 23 & 443 & 447 \\
\hline 240 & I 6.27 & 433 & 442 & 510 & II.O3 & 440 & 444 \\
\hline 255 & 15.93 & 434 & 444 & $\infty$ & $-5 \cdot 37$ & $\cdots$ & $\cdots$ \\
\hline & & & & & & Average, & 2447 \\
\hline
\end{tabular}

1 The decrease of the recalculated coefficients in the very beginning of the series in Tables V-VIII deserves no consideration, as there the coefficients are enormously affected by errors of $\alpha_{\circ}, \alpha$, and $t$. Under $t$ in these tables time is expressed in minutes.

${ }^{2}$ Based on $\alpha_{0}=22.22^{\circ}$.

3 The average coefficient, $0.00045^{6}$, would have resulted instead of $0.00047^{2}$ if the observed rotation had been not $21.83^{\circ}$, but $21.85^{\circ}$.

${ }^{4}$ Based on $\alpha_{0}=22.12^{\circ}$. 
Table VII.-Armstrong and Caldwell's Results (Loc. cit., p. i98) Recalctlated.

\begin{tabular}{|c|c|c|c|c|c|c|c|}
\hline $\begin{array}{l}t \\
\mathrm{o}\end{array}$ & $\begin{array}{c}\alpha . \\
{\left[46.38^{\circ}\right]}\end{array}$ & $\begin{array}{c}k\left(\mathbf{A} . \& \mathbf{C}_{\text {. })}{ }^{1}\right. \\
\ldots\end{array}$ & $\begin{array}{c}k(\text { recalc. }) \\
\ldots\end{array}$ & $\begin{array}{c}t . \\
290\end{array}$ & $\begin{array}{c}\alpha . \\
29.87\end{array}$ & $\begin{array}{l}k\left(\text { A. \& C.). }{ }^{1}\right. \\
0.000498\end{array}$ & $\begin{array}{l}k \text { (recalc.). } \\
0.000507\end{array}$ \\
\hline IO & $45 \cdot 47$ & 0.000428 & $(0.000692)$ & 300 & 29.08 & 495 & 504 \\
\hline 20 & 44.83 & $46 \mathrm{I}$ & (593) & 310 & 28.83 & 502 & 510 \\
\hline 30 & 44.20 & $47 \mathrm{I}$ & (559) & 320 & 28.42 & 500 & 508 \\
\hline 40 & 43.62 & 468 & (534) & 330 & 27.93 & 501 & 509 \\
\hline 50 & 42.97 & $47^{8}$ & $(53 \mathrm{I})$ & 340 & 27.43 & 503 & $5 \mathrm{II}$ \\
\hline 60 & $4^{2} \cdot 37$ & 479 & $(523)$ & 350 & 26.97 & 503 & $5 \mathrm{II}$ \\
\hline 70 & 4 I. 80 & 477 & 515 & 360 & 26.55 & $5 \circ 3$ & $5^{10}$ \\
\hline 80 & 4 I.I 7 & 482 & 515 & $37^{\circ}$ & 26.12 & 503 & $5 \mathrm{IO}$ \\
\hline 90 & 40.57 & $4^{8} 5$ & 514 & 380 & 25.65 & 504 & 4I I \\
\hline 100 & 40.07 & 488 & 505 & 390 & 25.25 & 504 & 510 \\
\hline I IO & $39 \cdot 45$ & 483 & 507 & 400 & 24.87 & 502 & 509 \\
\hline 120 & 38.85 & 486 & 508 & 4 10 & $24 \cdot 4^{2}$ & 503 & 509 \\
\hline I3O & 38.28 & 487 & 507 & 420 & 24.02 & 503 & 509 \\
\hline 140 & 37.67 & $49 \mathrm{I}$ & 509 & 430 & 23.62 & 503 & 509 \\
\hline I 50 & 37.13 & 490 & 508 & 440 & $23 \cdot 17$ & 504 & 5 10 \\
\hline 160 & 36.55 & 492 & 509 & 450 & 22.80 & 503 & 509 \\
\hline 170 & 36.03 & $49 \mathrm{I}$ & 507 & 460 & $22 \cdot 38$ & 504 & 510 \\
\hline 180 & $35 \cdot 43$ & 495 & 510 & $47 \circ$ & 21.93 & 506 & $5 \mathrm{II}$ \\
\hline 190 & 34.93 & 494 & 508 & 480 & 21.53 & 507 & 512 \\
\hline 200 & $34 \cdot 45$ & $49^{2}$ & 505 & 490 & 21.13 & 507 & 512 \\
\hline 210 & 33.87 & 495 & 508 & 500 & 20.77 & $5 \circ 7$ & 512 \\
\hline 220 & $33 \cdot 38$ & 494 & 506 & 510 & 20.40 & 507 & 512 \\
\hline 230 & 32.87 & 494 & 506 & 520 & 20.00 & 508 & 513 \\
\hline 240 & $32 \cdot 38$ & 494 & $5 \circ 5$ & 530 & I9. 68 & 506 & 5 II \\
\hline 260 & 3 I. 28 & 499 & 509 & $54^{\circ}$ & I9. 27 & 508 & 513 \\
\hline 270 & 30.80 & 499 & 508 & $\infty$ & -I I. I 2 & $\ldots$ & $\ldots$ \\
\hline 280 & $30.3^{8}$ & 496 & 506 & & & Average, & 509 \\
\hline
\end{tabular}

Table VIII.-Armstrong and Caldwell's Results (Loc. cit., p. i98) Recalculated.

\begin{tabular}{|c|c|c|c|c|c|c|c|}
\hline$t$ & $\alpha$. & $k(\mathrm{~A}, \& \mathrm{C} .)^{9}$ & $k$ (recalc.). & $t$ & $\alpha$ & $k(\mathrm{~A} . \& \mathrm{C} .)^{2}$ & $k$ (recalc.). \\
\hline 0 & {$\left[44.89^{\circ}\right]$} & $\ldots$ & & 230 & 3 I.I 3 & 0.000527 & 0.000537 \\
\hline 10 & 44.02 & 0.000481 & $(0.00068 \mathrm{I})$ & 240 & 30.65 & 526 & 534 \\
\hline 20 & $43 \cdot 37$ & 489 & $(600)$ & 250 & 30.13 & 527 & 535 \\
\hline 30 & $4^{2} \cdot 75$ & 493 & $(566)$ & 260 & 29.62 & 528 & 535 \\
\hline 40 & 42.20 & 487 & 539 & 270 & 29.08 & 530 & 537 \\
\hline 50 & $41 \cdot 5^{8}$ & 492 & $53 \mathrm{I}$ & 280 & 28.60 & 530 & 536 \\
\hline 60 & 40.93 & 500 & $53 \mathrm{I}$ & 290 & $28 . \mathrm{I} 5$ & 529 & 535 \\
\hline 70 & 40.30 & 505 & 533 & 300 & 27.63 & 530 & 537 \\
\hline 90 & 39.10 & 507 & $53^{\circ}$ & 310 & 27.22 & 528 & 535 \\
\hline 100 & 38.47 & 512 & 532 & 320 & $26.7^{2}$ & 530 & 536 \\
\hline I IO & 37.87 & 513 & $53 \mathrm{I}$ & 330 & 26.28 & 529 & 535 \\
\hline 120 & 37.28 & 5 I 5 & $53 \mathrm{I}$ & 340 & 25.83 & 529 & 535 \\
\hline 130 & 36.70 & 516 & $53 \mathrm{I}$ & 350 & $25 \cdot 32$ & 532 & 537 \\
\hline 140 & 36.13 & 516 & $53 \mathrm{I}$ & 360 & 24.88 & 532 & 536 \\
\hline 150 & $35 \cdot 53$ & 519 & 533 & 370 & 24.47 & $53 \mathrm{I}$ & 536 \\
\hline
\end{tabular}




\begin{tabular}{|c|c|c|c|c|c|c|c|}
\hline$t$ & $\alpha$ & $k(\mathrm{~A}, \& \mathrm{C}$.$) .$ & $k$ (recalc) & $t$ & a. & $k(\mathrm{~A} . \& \mathrm{C})$. & $k$ (tecalc.). \\
\hline 160 & 34.95 & 0.000521 & 0.000534 & 380 & 24.02 & $0.00053^{2}$ & 0.000537 \\
\hline 170 & 34.33 & 525 & 536 & 390 & 23.60 & $53 \mathrm{I}$ & $53^{6}$ \\
\hline 180 & $33 \cdot 78$ & 526 & 537 & 400 & 23.15 & 532 & 537 \\
\hline 190 & 33.25 & $5^{25}$ & 536 & 410 & $22 \cdot 73$ & 532 & 537 \\
\hline 200 & $3^{2} \cdot 73$ & $5^{25}$ & 535 & 420 & 22.35 & 531 & 536 \\
\hline 210 & 32.25 & $5^{23}$ & 532 & $\infty$ & -10.79 & $\ldots$ & $\cdots$ \\
\hline 220 & 31.65 & 527 & 536 & & & Average, & 0.000535 \\
\hline
\end{tabular}

To show how closely $\log _{10}\left(\alpha-\alpha_{\infty}\right)$ is represented by a linear function of $t$, we reproduce in Table IX the figures for one of Armstrong and Caldwell's series (the same as that of Table V). Under $\log _{10}\left(\alpha-\alpha_{\infty}\right)$ obs. are values based on the observations; under $\log _{10}(\alpha-\alpha \infty)$ calc. are values calculated from the equation

$$
\log _{10}\left(\alpha-\alpha_{\infty}\right)=\text { I.44I65 } 6.0004562 t \text {. }
$$

TABLE IX.

\begin{tabular}{|c|c|c|c|c|c|}
\hline$t$ & $\log _{10}\left(\alpha-\alpha_{0}\right)$ obs. & $\log _{10}\left(\alpha-\alpha_{0}\right)$ calc. & $t$ & $\log _{10}\left(\alpha-\alpha_{0}\right) \circ b s$ & $g_{10}\left(\alpha-\alpha_{0}\right)$ calc. \\
\hline I 5 & I. 4346 & I. 4348 & 255 & 1.3253 & I. 3253 \\
\hline 30 & I. 4276 & I. 4280 & 270 & I.3I $8 \mathrm{I}$ & I. 3185 \\
\hline 45 & I. $42 \mathrm{II}$ & I. $42 \mathrm{II}$ & 285 & I.310I & 1.3116 \\
\hline 60 & I.4I5O & I. 4 I 43 & 345 & I. 2842 & I. 2843 \\
\hline 75 & I. 4074 & I. $4 \bigcirc 74$ & 360 & I. 2774 & 1.2774 \\
\hline 90 & I. 4004 & I. 4006 & 375 & I. 2700 & 1.2706 \\
\hline 105 & I. 3948 & I. 3937 & 390 & I.2629 & I. 2637 \\
\hline 120 & I. 3869 & I. 3869 & 405 & I. $255^{8}$ & 1.2569 \\
\hline I35 & I. 3802 & I.380 r & 420 & I. 2502 & I. 2500 \\
\hline 150 & I. 3736 & I. 3732 & 435 & I. 2430 & I. 2432 \\
\hline 165 & I. 3672 & I. 3664 & $45^{\circ}$ & I. 2360 & I. 2364 \\
\hline I 80 & I. 3596 & I. 3595 & 465 & I. 2292 & I. 2295 \\
\hline 195 & I. 353 I & I. 3527 & 480 & I. 2225 & I. 2227 \\
\hline 210 & I. 3464 & I. $345^{8}$ & 495 & I. 2159 & I. $215^{8}$ \\
\hline 225 & I.3393 & I.3390 & 510 & I. 2087 & 1.2090 \\
\hline 240 & 1. 3332 & I. 3322 & 525 & I. 2028 & $1.202 \mathrm{I}$ \\
\hline
\end{tabular}

\section{Do Julius Meyer's Results Indicate Either Side Reactions or Deviation from the Law of Mass Action?}

Meyer's velocity coefficients show a great decrease. If the variation were here again due to an erroneous $\alpha_{o}$, it seemed reasonable to expect that the error was large enough to appear if the actual readings $\alpha$ were directly plotted against the corresponding times $t$. As a matter of fact, the accompanying figure, representing the data of Meyer's "Tabelle I8," 1 shows that the curve of $\alpha$ 's cannot possibly originate in the point representing the $\alpha_{0}$ assumed by Meyer.

Table X reproduces the same series of Meyer's and shows that with a

${ }^{1}$ Loc. cit., 62, 79. 
correct $\alpha_{\circ}$ the velocity coefficient ( $k$ recalculated) is constant within the errors of experiment. ${ }^{1}$

Table X.-One of Julius Meyer's Series (Loc. cit., 62, 79) Recalculated.

\begin{tabular}{|c|c|c|c|}
\hline$t(\min )$ & $\alpha$ & $k$ (Meyer).$^{2}$ & $k$ (recalc.) \\
\hline 0 & {$\left[65.09^{\circ}\right]$} & $\ldots$ & $\ldots$. \\
\hline 7 & $65.18(?)$ & 0.000302 & $\ldots$ \\
\hline 10 & $65.14(?)$ & $25^{8}$ & $\ldots \ldots$ \\
\hline 24 & 64.96 & I95 & 0.0000275 \\
\hline 38 & 64.88 & $15 \mathrm{I}$ & 280 \\
\hline 55 & 64.80 & II & 269 \\
\hline 72 & $64.7 \mathrm{I}$ & 106 & 269 \\
\hline 98 & $64 \cdot 58$ & 95 & 266 \\
\hline 296 & $63 \cdot 38$ & 79 & 297 \\
\hline 400 & 62.89 & 73 & 283 \\
\hline 430 & 62.81 & 70 & 270 \\
\hline I 500 & 57.20 & 67 & $28 \mathrm{I}$ \\
\hline \multirow[t]{2}{*}{$\infty$} & -20.28 & $\ldots$ & $\ldots$ \\
\hline & & Av & 0.0000277 \\
\hline
\end{tabular}

Armstrong and Caldwell's, Meyer's, and our own measurements thus demonstrate that sugar hydrolysis proceeds in accordance with the law of mass action, as a reaction strictly monomolecular with respect to sugar.

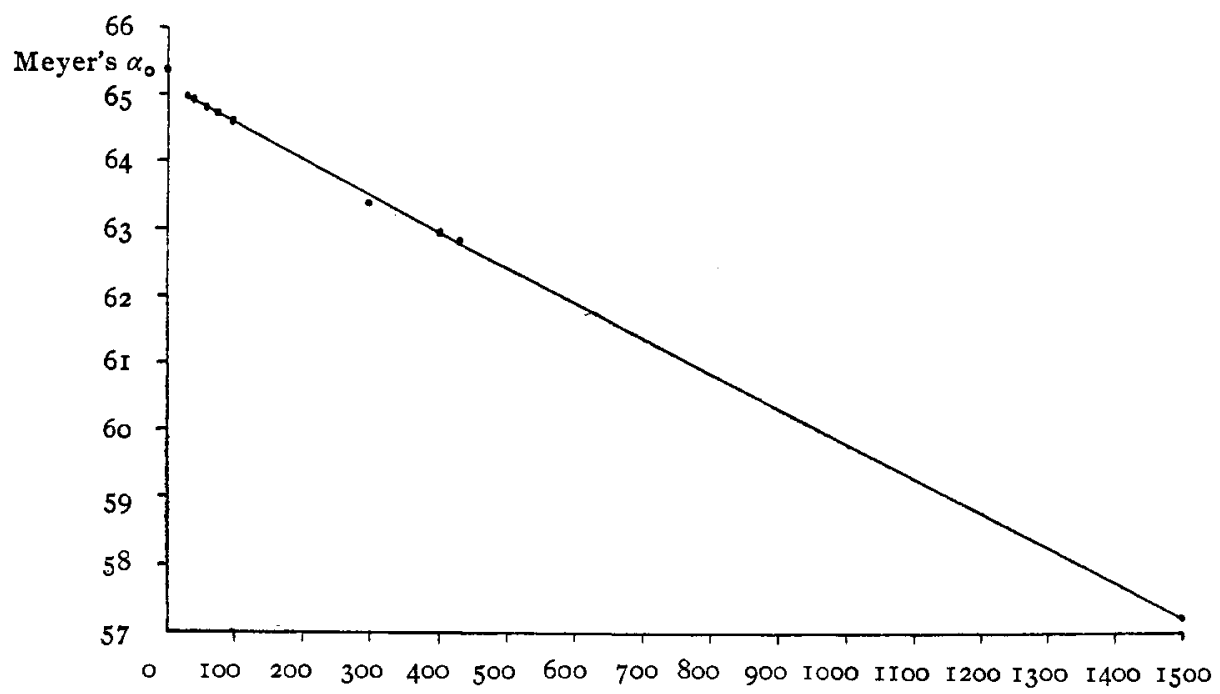

Side-reactions comparable in speed with the hydrolysis proper would manifest themselves in deviations from the monomolecular equation, and hence if mutarotation, for instance, accompanies the hydrolysis at

${ }^{1}$ See also Hudson, This Journal, 30, i i65 (igo8).

${ }^{2}$ Based on $\alpha_{0}=65.36^{\circ}$. 
all, it must reach completion with relatively great rapidity and may be left out of account. ${ }^{1}$

This may suggest the conclusion that the mechanism of sugar hydrolysis is correctly described by the ordinary stoichiometric equation, single uncombined sugar molecules being hydrolyzed by water rendered active by the hydrogen ions of the catalyzer. But such a conclusion is not necessarily right. Indeed, the reaction would still follow the monomolecular equation if each single molecule undergoing hydrolysis were not sugar itself, but a compound of one (not more than one) sugar molecule with molecules of one or more other substances.

\section{Does the Polariscope Show the True Composition of the Solution during Hydrolysis?}

Hudson ${ }^{2}$ points out that polarimetric analysis, which assumes that the partial rotations of sucrose, glucose, and fructose are proportional to their concentrations, involves a considerable error. The specific rotations of the three sugars vary appreciably with the concentrations, and that of fructose varies rapidly: "If the progress of the inversion is calculated from the polariscopic readings under the assumption that the specific rotation of fructose remains constant during the reaction, the velocity coefficient must be expected to increase."

The hydrolysis measurements discussed above exhibited no such increase; and so it seemed desirable to re-investigate the assumption that the rotation is a linear function of the percentage of sugar hydrolyzed. When our results were complete, a set of data on the subject were discovered in one of Ostwald's publications. ${ }^{3}$ But as our method permitted of reproducing the conditions of an actual hydrolysis experiment somewhat more closely than Ostwald's, ${ }^{4}$ it may not be superfluous to briefly mention our results.

Five solutions were made up containing the same amounts of water and acid as the solution of Table I (Section 2 above), viz., I 95.73 grams water and 28.750 grams formic acid, but respectively 7.500, I5.000, 22.500, 30.000, and 37.500 grams of sugar instead of the 50.500 grams contained in that solution. An exactly similar set of five solutions was prepared for control experiments, and the two sets were abandoned for hydrolysis at a moderate temperature. When the control solutions showed that in-

1 That in the absence of acids, when sugar is hydrolyzed by the enzyme invertase, mutarotation reactions do accompany the hydrolysis and proceed with a speed not very different from that of the hydrolysis itself, has been shown by O'Sullivan and Thompson, J. Chem. Soc., 57, 927 (I890), and by Hudson, This Journal, 30, I 160 (I908).

2 This Journal, 32, 888 (1910).

${ }^{8} \mathrm{~J}$. prakt. Chem., 29, 390 (1 884).

4 Ostwald measured the rotation of solutions of known cane and invert sugar content after eliminating the catalyzing acid. 
version was complete, the following amounts of cane sugar were added to the five principal solutions (taken in the same order as above): viz., $43.000,35.500,28.000,20.500$, and $\mathrm{I} 3.000$ grams. The temperature having been reduced to $30.00^{\circ}$, the five solutions were at that moment exactly like the solution of Table I at several stages of hydrolysis, with the percentages hydrolyzed precisely know11. It remained to ascertain the corresponding rotations. Hydrolysis had set in anew with the addition of sugar, and now a series of rotation readings were taken, at intervals of I hour, for periods of 15 to 20 hours. The desired "initial" readings were found by a simple extrapolation method. These readings lay unmistakably on a straight line, which was best represented by the equation

$$
\alpha=\alpha_{0}-0.01\left(\alpha_{0}-\alpha_{\infty}\right) p=78.19-0.9938 p,
$$

where $p$ is the percentage hydrolyzed. The equation gives: $\alpha_{0}=78.19^{\circ}$ and $\alpha_{\infty}=-2 \mathrm{I} .19^{\circ}$, in sufficient agreement, respectively, with the $\alpha_{\circ}=78.00^{\circ}$ required by the figures of Table I and the $\alpha_{\infty}=-21.15^{\circ}$ found by direct observation. ${ }^{1}$

\section{The Variation of the Specific Rotatory Power of Fructose.}

Ostwald's determinations, together with the results just mentioned, point to the conclusion that in a sugar solution in process of hydrolysis the specific rotation of fructose is constant.

Now, during hydrolysis the water concentration remains practically constant. On the other hand, in aqueous solutions of fructose used in a study of its rotatory power the water concentrations are varied together with those of the fructose itself. For instance, a 35 per cent. solution of fructose contains about 30 per cent. less water than an equal volume of a highly dilute solution. And so the idea suggested itself that the cause of the variation of the specific rotatory power of fructose may lie in the varying water content of the solutions employed.

By way of a first test of this idea, it was proposed to prepare a strong (about 35 per cent.) solution of fructose, and dilute it gradually with a solution of some other substance containing the same amount of water per unit volume as the fructose solution itself. In order to simplify the manipulations involved, it was decided to try as a diluting medium a solution of cane sugar of the same density as the fructose solution. Two such solutions were expected to prove nearly enough equal in water concentration and also to mix without contraction or expansion of volume.

An approximately Ioo-gram lot (undried) of Kahlbaum's fructose was dissolved in water, and the solution, diluted to $25^{\circ} \mathrm{cc}$. at $\mathrm{I} 7.5^{\circ}$, was abandoned for a considerable time, till at least the more rapid stages of mutarotation were over. It was then decolorized with boneblack in the

\footnotetext{
${ }^{1}$ In angular degrees the differences amount to only $0.06^{\circ}$ and $0.01^{\circ}$, respectively.
} 
cold. Its specific gravity at $17.5^{\circ}$, referred to water of the same temperature, was I.I5O2.

Next a solution of cane sugar of the same density was prepared by dissolving 98.496 grams (calculated by Arrhenius' formula) of sugar in water and diluting to $25^{\circ} \mathrm{cc}$. at $17.5^{\circ}$. A specific gravity determination at that temperature gave I.I5OI.

The quantities of water in the two solutions differed by less than I per cent. When equal samples of the two were mixed together, neither contraction nor expansion took place: the specific gravity of the mixture at $\mathrm{I} 7.5^{\circ}$ was found to be I.I 5 or.

It was thus possible, by mixing the two solutions in several different proportions, and abserving the rotations of the mixtures, to determin whether the partial rotations of the fructose solution were proportional to the quantities of that solution in the mixture, and hence whether the specific rotation of fructose remained constant.

If the partial rotation of the fructose solution is proportional to its percentage in the mixture, then the total rotation $(\alpha)$ must be a linear function of that percentage $(p)$. As a matter of fact, Table XI shows that the observed rotations are almost perfectly reproduced by the equation

$$
\alpha=24.54-0.5830 p,
$$

and hence, that the specific rotation of fructose in our mixtures was independent of its concentration. But this matter will be subjected here to further study.

TABLE XI.

$\begin{array}{cccc}\text { p. } & \text { abs. } & \alpha \text { calc. } & \text { Diff. } \\ 0.00 & +24.54^{\circ} & +24.54^{\circ} & \pm 0.00^{\circ} \\ 10.41 & +18.53 & +18.47 & -0.06 \\ 20.12 & +12.78 & +12.81 & +0.03 \\ 30.04 & +7.03 & +7.03 & \pm 0.00 \\ 40.23 & +1.09 & +1.09 & \pm 0.00 \\ 60.03 & -10.55 & -10.46 & +0.09 \\ 69.76 & -16.17 & -16.12 & +0.05 \\ 89.69 & -27.72 & -27.75 & -0.03\end{array}$

Worcestrer, Mass., Jüne, IgII.

\section{STUDIES IN CONDUCTIVITY. I. THE CONDUCTIVITY OF AM- MONIA IN (ANHYDROUS) FORMIC ACID. I. "FORMIC A CID HYDROLYSIS."}

By H. I. Schlesinger and R, P. Calvert. Received October 24, IgIr.

In recent years, a great deal of attention has been given to the study of non-aqueous solutions, especially from the point of view of the theory of ionization. While this work has covered a wide range of solvents, the 